\title{
Perinatal outcomes of high dose versus low dose oxytocin regimen used for labor induction and factors associated with adverse perinatal outcome in four hospitals of Ethiopia: a multicenter comparative study
}

Melese Gezahegn Tesemma ${ }^{1 *}$ D, Demisew Amenu Sori ${ }^{2}$ and Desta Hiko Gemeda ${ }^{3}$

\begin{abstract}
Background: There is limited evidence on effect of high and low dose oxytocin used for labor induction on perinatal outcomes. We compared perinatal outcomes among pregnant mothers who received the two different oxytocin regimens and identified risk factors associated with adverse perinatal outcomes.

Methods: Facility based comparative cross-sectional study was conducted in four hospitals of Ethiopia over eight month's period during 2017/2018 year with 216 pregnant women who received high and low dose oxytocin for labor induction. Socio-demographics, reproductive characteristics of mothers and perinatal outcomes data were collected and entered into Epi-data version 3.1 and then exported to SPSS version 20 for cleaning and analysis. Chisquare test and logistic regression were done to see the effect of different oxytocin regimens on perinatal outcome. The result was presented using $95 \%$ confidence interval of crude and adjusted odds ratios. P-value $<0.05$ was used to declare statistical significance.

Result: Higher adverse perinatal outcomes ( $29 \%$ vs. $13.9 \%, p=0.005$ ) and higher non-reassuring fetal heart rate pattern ( $23.1 \%$ vs. $7.4 \%, p=0.001$ ) was observed among mothers who received high dose oxytocin compared to mothers who received low dose oxytocin. Using high oxytocin dose [AOR $=2.4,95 \% \mathrm{Cl}: 1.1,5.5]$, caesarean birth $[\mathrm{AOR}=9.3,95 \% \mathrm{Cl}: 3.8,22.5]$, instrumental birth $[\mathrm{AOR}=7.7,95 \% \mathrm{Cl}: 2.1,27.8]$, and antepartum hemorrhage $[\mathrm{AOR}=$ 17.8, $95 \%$ Cl: 1.9, 168.7] were risk factors of adverse perinatal outcomes.
\end{abstract}

Conclusions: There was significance difference in the occurrence of adverse perinatal outcomes among pregnant mothers who received high and low dose of oxytocin. Using high dose oxytocin, antepartum hemorrhage, caesarean birth and instrumental birth were associated with increased risk of adverse perinatal outcomes. We recommend using low dose oxytocin for better perinatal outcomes.

Keywords: Labor induction, Oxytocin regimen, High dose oxytocin, Low dose oxytocin, perinatal outcome, adverse perinatal outcome

\footnotetext{
* Correspondence: get.melese@gmail.com

'Department of Obstetrics and Gynecology, Arsi University, Asella, Ethiopia

Full list of author information is available at the end of the article
}

C C The Author(s). 2021 Open Access This article is licensed under a Creative Commons Attribution 4.0 International License, which permits use, sharing, adaptation, distribution and reproduction in any medium or format, as long as you give appropriate credit to the original author(s) and the source, provide a link to the Creative Commons licence, and indicate if changes were made. The images or other third party material in this article are included in the article's Creative Commons licence, unless indicated otherwise in a credit line to the material. If material is not included in the article's Creative Commons licence and your intended use is not permitted by statutory regulation or exceeds the permitted use, you will need to obtain permission directly from the copyright holder. To view a copy of this licence, visit http://creativecommons.org/licenses/by/4.0/. The Creative Commons Public Domain Dedication waiver (http://creativecommons.org/publicdomain/zero/1.0/) applies to the data made available in this article, unless otherwise stated in a credit line to the data. 


\section{Background}

Labor induction is aimed at achieving vaginal birth when the benefits of giving birth out-weigh the risk of continuing the pregnancy to the mother and perinatal outcome $[1,2]$. Oxytocin is synthetic polypeptide hormone that is used to stimulate uterine contractions [2, 3]. Induction of labor (IOL) is associated with poorer perinatal outcomes when compared with spontaneous labor. There is a greater risk of neonatal and fetal complications like fetal heart rate decelerations, low 5-minute Apgar score, admission to a neonatal intensive care unit (NICU) and delayed initiation of breastfeeding [4].

Oxytocin regimen can be either high dose or low dose depending on the starting dose, the amount and rate of sequential increases in the dose of oxytocin [5]. Intervals to increase oxytocin doses vary from 15 to $60 \mathrm{~min}$ in different trials [6-9]. Starting dose of high-dose regimes ranged from 4 to $10 \mathrm{mili}-$ Unit/ minute $(\mathrm{mU} / \mathrm{min})$ while that of low dose ranges from 1 to $4 \mathrm{mU} / \mathrm{min}$ [5]. Even though Ethiopian national guideline and other study recommends use of low dose oxytocin regimen for labor induction ([3], Management Protocol on Selected Obstetric Topics: Federal Democratic Republic Of Ethiopia, Ministry Of Health, unpublished), there are also centers which are utilizing high dose oxytocin regimen one of which is Jimma university medical center (JUMC) (Segni H, Niguse D. et al:: Obstetrics management guideline in JUSH Jimma University, unpublished).

To date, there is no strong recommendation of a particular dosage of oxytocin regimen for labor induction [10-12]. Although there are few studies conducted on outcomes of induction using oxytocin in Ethiopia, there is no evidence that compares the effect of high dose and low dose oxytocin regimen on perinatal outcomes. This study was therefore aimed at determining the effects of oxytocin regimens on perinatal outcomes by comparing high dose and low dose oxytocin regimens.

\section{Method \& Material}

\section{Study area, study period and study design}

Facility based comparative cross-sectional study was conducted in four hospitals of Ethiopia namely Jimma University Medical Centre (JUMC), Shanan Gibe general hospital, Arbaminch General Hospital and Kuyu General Hospital over eight months period during 2017/2018 year. JUMC is a tertiary teaching hospital with high birth rate capacity about 4300 births per year and uses high dose oxytocin regimen while the other three were with lower birth rate capacity utilizing low dose oxytocin regimen. Arbaminch general hospital has 1500 births per year, Kuyu general hospital about 1350 births per year and Shenen gibe general hospital has nearly 1400 births per year. The methodology used in the current study is similar to that of another study related to the same project which has been published in BMC Pregnancy and Childbirth [13].

\section{Study population}

Pregnant women with singleton gestations who undergo induction of labor at term and beyond were included. Pregnant mothers with Intra Uterine Fetal Death (IUFD), critically ill pregnant mothers, pregnant mothers with lethal congenital anomaly, pregnancies complicated by cord prolapse, induced pregnancy for whom cesarean section (CS) was done for non-obstetric indication like social reason were excluded from the study[13].

\section{Sample size \& sampling technique}

The required sample size was determined by using double population proportion using Epi info 7 software, considering the following parameters: Proportion of non-reassuring fetal heart rate patterns (NRFHRP) among laboring mothers who received high dose of oxytocin $(54.16 \%)$ and low dose of oxytocin (34.37\%) [9], $5 \%$ level of significance, power of $80 \%$ and $1: 1$ ratio of exposed to un-exposed. Thus total sample size will be 196. Adding $10 \%$ for non-response, 216 laboring mothers were recruited for the study. Thus, 108 pregnant women were selected from JUMC while the rest 108 pregnant women were recruited from three general hospitals. All pregnant women who had undergone induction of labor during study period were recruited consecutively using the inclusion criteria.

\section{Data collection, entry and analysis}

Socio-demographics, reproductive characteristics of mothers and perinatal outcomes data were collected and entered into Epi-data version 3.1 and then exported to SPSS version 20 for cleaning and analysis. Chi-square test and logistic regression were done to see the effect of different oxytocin regimens on perinatal outcome. Variables showing association on bivariate analysis whose Pvalues were $<0.25$ were taken to multivariate regression model to control the confounding factors. The result was presented using $95 \%$ confidence interval of crude and adjusted odds ratios. P-value $<0.05$ was used to declare statistical significance.

\section{Ethical considerations}

Ethical clearance to conduct the research was obtained from institutional review board of Jimma University and written consent was obtained from study participants. All the information collected from the study participants were handled confidentially by omitting their personal identifiers and the data were used for the research purpose only. Participants were told by the language they understand that they have the right to participate in or withdraw from the study. All methods were performed 
in accordance with the relevant guidelines and regulations in accordance with Helsinki declarations.

\section{Operational definitions}

In this research, the following operational definitions were used.

\section{Non reassuring fetal heart rate patterns}

fetal heart rate pattern of either persistent category II or category III unresponsive to conservative measures necessitating immediate delivery.

\section{Advanced neonatal resuscitation}

a newborn who required supplemental oxygen, sucking meconium from oropharynx and intubation immediately after birth.

\section{Low APGAR score}

First minute APGAR less than 5 or fifth minute APGAR score of less than 7 .

\section{Neonatal sepsis}

Any infection in the neonate occurring within 28 days of birth.

\section{Adverse perinatal outcomes}

A neonate with one of the following adverse perinatal outcomes but not limited to: low APGAR score, admission to NICU, meconium at birth, need of advanced resuscitation, neonatal sepsis, early neonatal death.

\section{Low dose oxytocin regimen}

Initial dose of $2 \mathrm{mU} / \mathrm{min}$ increased by $2 \mathrm{mU} / \mathrm{min}$ every $30 \mathrm{~min}$ up to a maximum of $40 \mathrm{mU} /$ minute [13].

\section{High dose oxytocin regimen}

Initial dose of $6 \mathrm{mU} / \mathrm{min}$ increased by $6 \mathrm{mU} / \mathrm{min}$ every $20 \mathrm{~min}$ up to a maximum dose of $92.8 \mathrm{mU} / \mathrm{min} \mathrm{[13].}$

\section{Results}

Socio-demographic characteristics of study participants

We have enrolled two hundred sixteen laboring mothers to this study. The mean age of study participants was 26 years. One fifth $(18.5 \%, 40 / 216)$ of laboring mothers were illiterate. Majority138 (64\%) of the study participants were living in urban area with comparable distribution to the two study groups. Out of 216 participants, $128(59.3 \%))$ of inductions were conducted for premature rupture of membrane (PROM) while 49 (22.7\%,) were conducted for hypertensive disorder of pregnancy (HDP). Mean weight of newborns was 3260gm (SD + 449). Surprisingly equal number of male and female neonates was delivered in both groups with male to female ratio of 1.3:1 (Table 1 ).
Table 1 Socio-demographic and reproductive characteristics of the participants in four hospitals, October 1, 2017 to May 30, 2018

\begin{tabular}{|c|c|c|c|c|}
\hline \multirow[t]{2}{*}{ Variables } & \multirow[t]{2}{*}{ Category } & \multicolumn{2}{|c|}{ Type of oxytocin regimen } & \multirow{2}{*}{$\begin{array}{l}\text { Total No } \\
(\%) \\
N=216 \\
\mathrm{n}(\%)\end{array}$} \\
\hline & & $\begin{array}{l}\text { High dose } \\
(N=108) \\
\mathrm{n}(\%)\end{array}$ & $\begin{array}{l}\text { Low dose } \\
(N=108) \\
\mathrm{n}(\%)\end{array}$ & \\
\hline \multirow[t]{3}{*}{ Age in years } & $<=19$ & $4(3.7)$ & $5(4.6)$ & $9(4.2)$ \\
\hline & $20-29$ & $76(70.4)$ & $81(75.0)$ & $157(72.7)$ \\
\hline & $\geq 30$ & 28(25.9) & $22(20.4)$ & $50(33.1)$ \\
\hline \multirow[t]{6}{*}{ Ethnicity } & Oromo & $60(55.6)$ & $56(51.9)$ & 116(53.7) \\
\hline & Amhara & $27(25)$ & $8(7.4)$ & $35(16.2)$ \\
\hline & Gamo & $0(0)$ & $23(21.3)$ & $23(10.6)$ \\
\hline & Dawro & $5(4.6)$ & 12(11.1) & $17(7.9)$ \\
\hline & Gurage & $9(8.3)$ & $4(3.7)$ & $13(6.0)$ \\
\hline & Others & $7(6.5)$ & $5(4.6)$ & $12(5.6)$ \\
\hline \multirow[t]{2}{*}{ Parity } & Nulliparous & $56(51.9)$ & 32 (29.6) & $88(40.7)$ \\
\hline & Multipara & $52(48.1)$ & $76(70.4)$ & $128(59.3)$ \\
\hline Monthly income & In USD & 181 & 151 & 166 \\
\hline \multirow[t]{2}{*}{ Sex of newborn } & Male & $61(56.5)$ & $61(56.5)$ & $122(56.5)$ \\
\hline & Female & $47(43.5)$ & $47(43.5)$ & $94(43.5)$ \\
\hline
\end{tabular}

Of all 216 babies born, three neonates has complicated by early neonatal death. Overall, adverse perinatal outcomes were observed among $47(21.8 \%)$ of study participants. Of these 47 neonates with adverse neonatal outcomes, 32(68\%) were observed among high dose group (HDG) while the remaining 15(32\%) of adverse perinatal outcome were observed among low dose group (LDG). Common adverse perinatal outcomes were NRFHRP, 33 (15.3\%) followed by need for advanced neonatal resuscitation, 20 (9.3\%), thick meconium, 19 (8.8\%) and need of referral to NICU, 16 (7.4\%) (Table 2).

On cross-tabulation, occurrence of NRFHRP and composite adverse perinatal outcome has showed significant relation with use of different oxytocin regimens while other outcome variables like thick meconium at birth, need of advanced neonatal resuscitation, need of referral to NICU, first minute APGAR < 5, Fifth minute APGAR < 7 , Neonatal life status on discharge showed no stastical relation. Accordingly, prevalence of NRFHRP were 23.1 and $7.4 \%(P=0.001)$ among HDG and LDG respectively while overall prevalence of adverse perinatal outcomes was 29.6 and $13.9 \%(P=0.005)$ respectively (Table 2$)$.

\section{Factors associated with adverse perinatal outcome}

On bivariate logistic regression residence, misoprostol use, and neonatal weight, uterine hyper stimulation did not show any kind of association with adverse perinatal outcome while maternal age $<19$ years $[\mathrm{COR}=4.4$, $95 \% \mathrm{CI}: 1.0,19.4]$, oxytocin regimen $[\mathrm{COR}=2.6,95 \% \mathrm{CI}$ : 1.3, 5.2], caesarean birth $[\mathrm{COR}=9.0,95 \%$ CI:4.0, 20.6], 
Table 2 Cross-tabulation of perinatal outcomes among participants with high dose and low dose oxytocin regimen in four hospitals, October 1, 2017 to May 30, 2018

\begin{tabular}{|c|c|c|c|c|}
\hline \multirow[t]{2}{*}{ Perinatal Outcomes } & \multirow[t]{2}{*}{ Response } & \multicolumn{2}{|l|}{ Oxytocin Regimen } & \multirow{2}{*}{$\begin{array}{l}P \text { - } \\
\text { Value }\end{array}$} \\
\hline & & High Dose $(N=108)$ n (\%) & Low Dose $(N=108) n(\%)$ & \\
\hline \multirow[t]{2}{*}{ Adverse neonatal outcome } & Yes & $32(29.6)$ & 15(13.9) & \multirow[t]{2}{*}{0.005} \\
\hline & No & $76(70.4)$ & $93(86.1)$ & \\
\hline \multirow[t]{2}{*}{ Non-reassuring fetal heart rate pattern } & Yes & $25(23.1)$ & $8(7.4)$ & \multirow[t]{2}{*}{0.001} \\
\hline & No & $83(76.9)$ & 100(92.6) & \\
\hline \multirow[t]{2}{*}{ 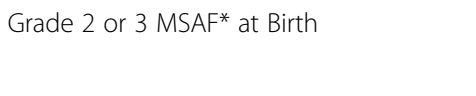 } & Yes & $12(11.1)$ & $7(6.5)$ & \multirow[t]{2}{*}{0.230} \\
\hline & No & $96(88.9)$ & $101(93.5)$ & \\
\hline \multirow[t]{2}{*}{ Advanced neonatal resuscitation needed } & Yes & $14(13)$ & $6(5.6)$ & \multirow[t]{2}{*}{0.06} \\
\hline & No & $94(87)$ & $102(94.4$ & \\
\hline \multirow[t]{2}{*}{ Neonate referred to $\mathrm{NICU}^{*}$} & Yes & 10(9.3) & $6(5.6)$ & \multirow[t]{2}{*}{0.299} \\
\hline & No & $98(90.7)$ & $102(94.4)$ & \\
\hline \multirow[t]{2}{*}{ First minute APGAR } & APGAR $<5$ & $1(0.9)$ & $2(1.9)$ & \multirow[t]{2}{*}{$1.000^{*}$} \\
\hline & APGAR $>=5$ & $107(99.1)$ & $106(98.1)$ & \\
\hline \multirow[t]{2}{*}{ Fifth minute APGAR } & APGAR $<7$ & $1(0.9)$ & $4(3.7)$ & \multirow[t]{2}{*}{$0.369^{*}$} \\
\hline & APGAR $>=7$ & $107(99.1)$ & $104(96.3)$ & \\
\hline \multirow[t]{2}{*}{ Outcome of neonate on discharge } & Alive & $107(99.1)$ & $106(98.1)$ & \multirow[t]{2}{*}{$1.00^{*}$} \\
\hline & Dead (ENND) & $1(0.9)$ & $2(1.9)$ & \\
\hline
\end{tabular}

*Fisher's Exact Test was used.

instrumental birth $[\mathrm{COR}=7.895 \% \mathrm{CI}: 2.6,23.7]$, unfavorable Bishop score [ COR $=3,95 \%$ CI:1.3,6.6] presence of adverse maternal outcome $[\mathrm{COR}=2.8,95 \% \mathrm{CI}$ : $1.1,7.1]$ and $\mathrm{APH}$ as indication $[\mathrm{COR}=8.8,95 \% \mathrm{CI}:(1.3$, 57.0)] has showed statistically significant association with occurrence of adverse perinatal outcome at P-Value $<$ 0.05 (Table 3).

However, on multivariate model, only high dose oxytocin regimen $[\mathrm{AOR}=2.4,95 \% \mathrm{CI}$ : 1.1, 5.5], Caesarean birth $[\mathrm{AOR}=9.3,95 \% \mathrm{CI}: 3.8,22.5]$, instrumental birth [AOR $=7.7,95 \% \mathrm{CI}: 2.1,27.8]$, APH as indication for induction $[\mathrm{AOR}=17.8,95 \% \mathrm{CI}$ : $(1.9,168.7)]$ were found to be associated with adverse perinatal outcome at $P$ value $<0.05$ (Table 3 ).

\section{Discussion}

Using high dose oxytocin was associated with increased risk of developing adverse perinatal outcomes by 2.5 times compared to low dose oxytocin regimen. Neonates born from laboring mothers who received high dose of oxytocin were more at risk of developing adverse neonatal outcomes. This finding was inconsistent with other studies that showed no significant difference on perinatal outcomes with regard to oxytocin regimen $[5,7,9,11$,

Table 3 Risk factors associated with poor neonatal outcomes in four hospitals, October 1, 2017 to May 30, 2018

\begin{tabular}{|c|c|c|c|c|c|c|c|}
\hline \multirow[t]{2}{*}{ Variables } & \multirow[t]{2}{*}{ Category } & \multicolumn{2}{|c|}{ Adverse neonatal outcomes } & \multirow{2}{*}{$\begin{array}{l}\text { COR } \\
(95 \% \mathrm{Cl})\end{array}$} & \multirow{2}{*}{$\begin{array}{l}P \text { - } \\
\text { value }\end{array}$} & \multirow{2}{*}{$\begin{array}{l}\text { AOR } \\
(95 \% \mathrm{Cl})\end{array}$} & \multirow{2}{*}{$\begin{array}{l}P \text { - } \\
\text { value }\end{array}$} \\
\hline & & $\begin{array}{l}\text { Yes } \\
\text { n (\%) }\end{array}$ & $\begin{array}{l}\text { No } \\
\text { n (\%) }\end{array}$ & & & & \\
\hline \multirow[t]{2}{*}{ Oxytocin regimen } & High dose & $32(29.6)$ & $76(70.4)$ & $2.6(1.3,5.2)$ & 0.006 & $2.4(1.0,5.5)$ & $0.039^{*}$ \\
\hline & Low dose & 15(13.9) & $93(86.1)$ & 1 & & 1 & \\
\hline \multirow[t]{3}{*}{ Mode of birth } & CS & $30(41.7)$ & $42(58.3)$ & $9.0(4.0,20.6)$ & 0.000 & $9.4(3.8,22.8)$ & $0.000^{*}$ \\
\hline & Instrumental & $8(38.1)$ & 13(61.9) & $7.8(2.6,23.7)$ & 0.000 & $7.8(2.2,28.3)$ & $0.002^{*}$ \\
\hline & SVD & $9(7.3)$ & 114(92.8) & 1 & & 1 & \\
\hline \multirow[t]{5}{*}{ Indication for induction } & PROM & 25(19.5) & 103(80.5) & $0.9(0.3,2.3)$ & 0.751 & $1.0(0.3,3.2)$ & 0.943 \\
\hline & $\mathrm{HDP}$ & $8(16.3)$ & $41(83.7)$ & $0.7(0.2,2.2)$ & 0.527 & $0.6(0.1,2.0)$ & 0.373 \\
\hline & $\mathrm{APH}$ & $5(71.4)$ & $2(28.6)$ & $8.8(1.3,57.0)$ & 0.023 & $17.8(1.9,168.7)$ & $0.012^{*}$ \\
\hline & Chorio-amnionitis & $3(60)$ & $2(40)$ & $5.3(0.7,39.0)$ & 0.105 & $9.0(0.8,97.0)$ & 0.071 \\
\hline & Post term & $6(22.2)$ & $21(77.8)$ & 1 & & 1 & \\
\hline
\end{tabular}


12] and one other study that showed decreased risk of neonatal sepsis with high dose oxytocin [14]. The increased risk of adverse perinatal outcome observed in our study can be explained by the fact that high dose oxytocin is associated with uterine hyper-systole $[5,6]$ and non- reassuring fetal heart rate patterns [12] that in turn negatively affects the perinatal outcomes. In this study it was found that prevalence of NRFHRP were 3.1 times higher among HDG than LDG. NRFHRP, being one element of composite adverse perinatal outcome might have contributed to this increased risk of adverse perinatal outcome among HDG.

Cesarean birth and instrumental birth were also associated with increased risk of developing adverse perinatal outcomes by 9.4 times and 8 times compared to vaginal mode of birth in this study. This is consistent with other studies that showed increased risk of perinatal morbidities $[15,16]$. One study showed increased risk of fetal scalp bruises and caput succedaneum with operative vaginal birth compared with spontaneous vaginal birth[15] while other study showed significantly higher rates of intracranial hemorrhage, brachial plexus, facial nerve injury, seizure, low 5-minute Apgar score, assisted ventilation among operative deliveries compared with spontaneous vaginal birth [16]. The other justification might be the indications to do $\mathrm{C} / \mathrm{S}$ or to apply instrument might have contributed for this increased risk of adverse perinatal outcome. In this study, nearly half of $\mathrm{C} / \mathrm{S}$ and instrumental birth were performed for nonreassuring fetal heart rate pattern; and $70 \%$ of adverse perinatal outcomes was attributed to non-reassuring fetal heart rate pattern. With regard to $\mathrm{C} / \mathrm{S}$, during $\mathrm{C} / \mathrm{S}$ the fetus may develop some anesthesia related complications.

Similarly, antepartum hemorrhage (APH) as indication of IOL was associated with increased risk of developing poor perinatal outcomes by 18 times compared to postterm indication. The fact that APH chiefly abruptionplacenta, causes severe perinatal morbidities, severe neonatal acidaemia \& cerebral palsy might have led to poor perinatal outcomes [1]. It is not uncommon to find hypoxia-associated periventricular leukomalacia and sudden infant death syndrome in newborns given birth after placental abruptions [1]. So, presence of APH has something to do with increment of adverse perinatal outcome. We didn't find any more literature that has similar intent to compare with on this finding. Thus, this finding can be used as a base line data for future studies.

The limitation to this study was, it was conducted in a teaching and public health facilities where complicated pregnancies come to tertiary center JUMC in this case. The parity of the study participants were not matched among the two groups proportion of primi-gravida being higher at high dose center. It is known that primi- gravidity is associated with higher adverse perinatal outcome compared with multiparas. These two factors might have affected the finding.

It was found that oxytocin regimen didn't show significant association with induction success and adverse maternal outcome in another article of the same project unlike adverse perinatal outcome that increase with high dose oxytocin $[13,17]$.

\section{Conclusions}

High dose oxytocin regimen, antepartum hemorrhage, caesarean delivery and instrumental delivery were associated with increased risk of developing adverse perinatal outcomes. The study favored use of low dose oxytocin as it's associated with decreased risk of adverse perinatal outcomes without affecting induction success and maternal outcome.

\section{Abbreviations}

APH: Ante Partum Hemorrhage; AOR: Adjusted odds ratio; ARM: Artificial Rupture of Membranes; Cl: Confidence Intervals; CPD: Cephalo Pelvic Disproportion; COR: Crude odds ratio; C/S: Caesarean Section; DPM: Drop Per Minute; HDG: High dose group; IOL: Induction of labor; JUMC: Jimma University Medical Centre; LDG: Low dose group; mu/min: Mili-unit/minute; NRFHRP: Non reassuring fetal heart rate patterns; PROM: Premature rupture of membrane; SPSS: Statistical Package for Social Scientists

\section{Acknowledgements}

We would like to acknowledge the study participants for providing us the necessary personal information and Jimma University medical center for allowing us retrieve patients chart.

\section{Authors' contributions}

M.G.T, D.A.S and D.H.G participated in the design and analysis of the study. M.G.T searched the databases, and wrote the first and second draft of article and analyzed the finding. D.A.S and D.H.G reviewed proposal development activities and each drafts of the result article. All authors revised the manuscript and approved the final version.

\section{Funding}

There is no funding source for this research.

\section{Availability of data \& materials}

The data used to generate and or analyze the current study are available from the corresponding author upon the request.

\section{Declarations}

Ethics approval and consent to participate

An official letter was obtained from the Institutional Review Board of Jimma University with reference number of IHRPGD/122/18 to conduct this research and we got permission letter from each hospital directors to collect data. Written informed consent was obtained from each study participant themselves as all of the them were greater than 18years old. All methods were performed in accordance with the relevant guidelines and regulations (accordance with the Declaration of Helsinki).

Consent for publication

Not applicable for this publication.

Competing interests

We declare that we don't have competing interests with publication of this article. 


\section{Author details}

'Department of Obstetrics and Gynecology, Arsi University, Asella, Ethiopia. ${ }^{2}$ Department of Obstetrics and Gynecology, Jimma University medical center, Jimma, Ethiopia. ${ }^{3}$ Department of Epidemiology, Jimma university Institute of health, Jimma, Ethiopia.

Received: 20 December 2020 Accepted: 13 August 2021

Published online: 28 August 2021

\section{References}

1. Deborah AW, Lili S. Abnormal Labor and Induction of Labor. In: Steven GG, Jennifer RN, Joe LS, et al. Obstetrics: Normal and Problem Pregnancies, 7th edition. China: Philadelphia: Elsevier, 2017. p. 276-83.

2. American College of Obstetricians and Gynecologists. Induction of labor. ACOG practice bulletin \#107. Obstet Gynecol. 2009;114:386-97. https://doi. org/10.1097/AOG.0b013e3181b48ef5.

3. Crane JMG, Young DC. Meta-analysis of low-dose versus high dose oxytocin for labor induction. J SOGC. 1998;20(13):1215-23. Available at https://doi. org/10.1016/50849-5831(16)31001-1.

4. Vogel JP, Souza JP, Gulmezoglu AM. Patterns and Outcomes of Induction of Labor in Africa and Asia: A Secondary Analysis of the WHO Global Survey on Maternal and Neonatal Health. PLoS ONE. 2013;8(6):e65612. https://doi. org/10.1371/journal.pone.0065612.

5. Wei SQ, Luo ZC, Qi HP, Xu H, Fraser WD. High-dose vs low-dose oxytocin for labor augmentation: a systematic review. Am J Obstet Gynecol. 2010; 203(4):296-304.https://doi.org/10.1016/j.ajog.2010.03.007. Epub 2010 May 8. PMID: 20451894

6. Satin AJ, Leveno KJ, Sherman ML, McIntire D. High-dose oxytocin: 20 versus 40-minute dosage interval. Obstet Gynecol. 1994;83(2):234-8. https://doi. org/10.1016/0091-2182(94)90138-4.

7. Merrill DC, Zlatnik FJ. Randomized, double-masked comparison of oxytocin dosage in induction and augmentation of labor. Obstet Gynecol. 1999;94(3): 455-63. https://doi.org/10.1016/s0029-7844(99)00338-5.

8. Xenakis EM, Langer O, Piper JM, Conway D, Berkus MD. Low-dose versus high-dose oxytocin augmentation of labor-a randomized trial. Am J Obstet Gynecol. 1995;173:1874-8

9. Satin AJ, Hankins GD, Yeomans ER. A prospective study of two dosing regimens of oxytocin for the induction of labor in patients with unfavorable cervices. Am J Obstet Gynecol. 1991;165(4) Pt 1):980-4. https://doi.org/10.1 016/0002-9378(91)90453-X.

10. Mori R, Tokumasu H, Pledge D, Kenyon S. High dose versus low dose oxytocin for augmentation of delayed labour. Cochrane Database Syst Rev. 2011;(10):CD007201. https://doi.org/10.1002/14651858.CD007201.pub2.

11. Alessandro G, Diann W, Victoria K, John CP, Sarah HP. Effects of two different protocols of oxytocin infusion for labor induction on obstetric outcomes: a cohort study. OJOG 2012, 2, 106-111 https://doi.org/10.4236/ ojog.2012.22020

12. Budden $A$, Chen LJY, Henry A. High-dose versus low-dose oxytocin infusion regimens for induction of labor at term. Cochrane Database Syst Rev. 2014; (10):CD009701. https://doi.org/10.1002/14651858.CD009701.pub2.

13. Tesemma MG, Sori DA, Gemeda DH. High dose and low dose oxytocin regimens as determinants of successful labor induction: a multicenter comparative study. BMC Pregnancy and Childbirth (2020) 20:232.

14. Satin AJ, Leveno KJ, Sherman ML, Brewster DS, Cunningham FG. High versus low-dose oxytocin for labor stimulation. Obstet Gynecol. 1992;80(1):111-6

15. Lawani LO, Anozie OB, Ezeonu PO, lyoke CA. Comparison of outcomes between operative vaginal deliveries and spontaneous vaginal deliveries in southeast Nigeria. Int J Gynaecol Obstet. 2014;125(3):206-9. https://doi.org/1 0.1016/.i.jgo.2013.11.018.

16. Gardella C, Taylor M, Benedetti T, Hitti J, Critchlow C. The effect of sequential use of vacuum and forceps for assisted vaginal delivery on neonatal and maternal outcomes. Am J Obstet Gynecol. 2001;185(4):896902. https://doi.org/10.1067/mob.2001.117309.

17. Tesemma MG, Sori DA, Gemeda DH (2021). Maternal outcomes of high dose vs low dose oxytocin regimen used for labor induction in Ethiopia: a multicenter comparative study. Gynecol Obstet (Sunnyvale). 11: 553.

\section{Publisher's Note}

Springer Nature remains neutral with regard to jurisdictional claims in published maps and institutional affiliations.

Ready to submit your research? Choose BMC and benefit from:

- fast, convenient online submission

- thorough peer review by experienced researchers in your field

- rapid publication on acceptance

- support for research data, including large and complex data types

- gold Open Access which fosters wider collaboration and increased citations

- maximum visibility for your research: over $100 \mathrm{M}$ website views per year

At $\mathrm{BMC}$, research is always in progress.

Learn more biomedcentral.com/submissions 